\title{
INTERNET, SOCIEDADE E COMUNICACIÓN EN GALICIA
}

Manuel Gago

Xosé López

Xosé Pereira

Universidade de Santiago de Compostela

Doi:10.17075/aceg.2016.006 



\section{INTRODUCIÓN}

O último bienio da vida de Internet supuxo un claro avance cara á interactividade e á participación constante da audiencia en todos os procesos de comunicación. O fenómeno da «autocomunicación», tal e como o concibe Manuel Castells, supuxo unha transformación clara sobre a cidadanía nos procesos de comunicación, especialmente no referido á emisión de mensaxes. Neste escenario, cómpre analizar polo miúdo tres variables que son as que se propoñen neste artigo. Primeiro, as posibilidades de conexión reais que ten a cidadanía galega para poder falar claramente de potencialidades reais da Sociedade da Información e do Coñecemento nun territorio concreto e definido como Galicia. Segundo, os usos que se fan desas posibilidades, prestando unha especial atención á mocidade, sen dúbida o principal motor de cambio de todo este proceso. Finalmente, debemos analizar a reacción que están tendo os medios de comunicación tradicionais ante o novo escenario.

Diciamos hai dous anos que o contexto, daquela, estaba marcado por unha fonda crise económica. Lamentablemente, esta situación continuou dun xeito máis ou menos constante durante os anos 2013 e 2014. Esta situación provocou serios problemas en grupos de comunicación moi consolidados, pero tamén abriu novas oportunidades a proxectos, moito máis modestos na súa concepción, que lograron abrirse un importante oco no consumo e na participación dos usuarios. Ademais, a tecnoloxía avanzou cara á conectividade global, a calquera hora e en calquera lugar, creando varios trebellos móbiles que permiten un uso moito máis compulsivo das ferramentas de conexión.

Estas novidades afondan na estratexia xa definida nos albores do século XXI, cando os protagonistas deixaron de ser os medios de referencia e as grandes figuras do xornalismo para centrarse no usuario e nas súas posibilidades. Por esas razóns, cómpre analizar polo miúdo como está afrontando a sociedade galega estes novos conceptos de conectividade global, de consumo activo e de consumo informativo a través de fluxos ininterrompidos de información.

\section{SITUACIÓN ACTUAL DA SOCIEDADE DA INFORMACIÓN}

A porcentaxe de conectividade a Internet da sociedade galega xa se aproxima ao sesenta por cento, cun incremento escaso pero constante ao longo dos anos que só se viu alterado por un salto de catro puntos entre o ano 2013 e 2014. Non obstante, Galicia segue sendo unha das comunidades autónomas con menor penetración de Internet, lonxe do 77 \% de penetración de Cataluña ou Madrid. Na actualidade, en Galicia un 58,3 \% da cidadanía conéctase con frecuencia a Internet en calquera das súas múltiples posibilidades, o que supón unha poboación de 1,6 millóns de persoas. Esta tendencia é a habitual desde a aparición de estatísticas sobre o uso de Internet en Galicia no ano 1997 e, de feito, é a tecnoloxía que máis avanza na súa penetración no fogar, xunto á televisión, que acada a cota do $87,1 \%$.

Porén, a comunidade galega quedou relegada á última posición neste indicador, incluso das comunidades que tradicionalmente ocuparon os últimos postos, que eran Estremadura e Cantabria.

1 Datos de Kantar Media de marzo de 2015 para Galicia. 
Gráfico 1. Porcentaxe de usuarios de Internet en España no ano 2015

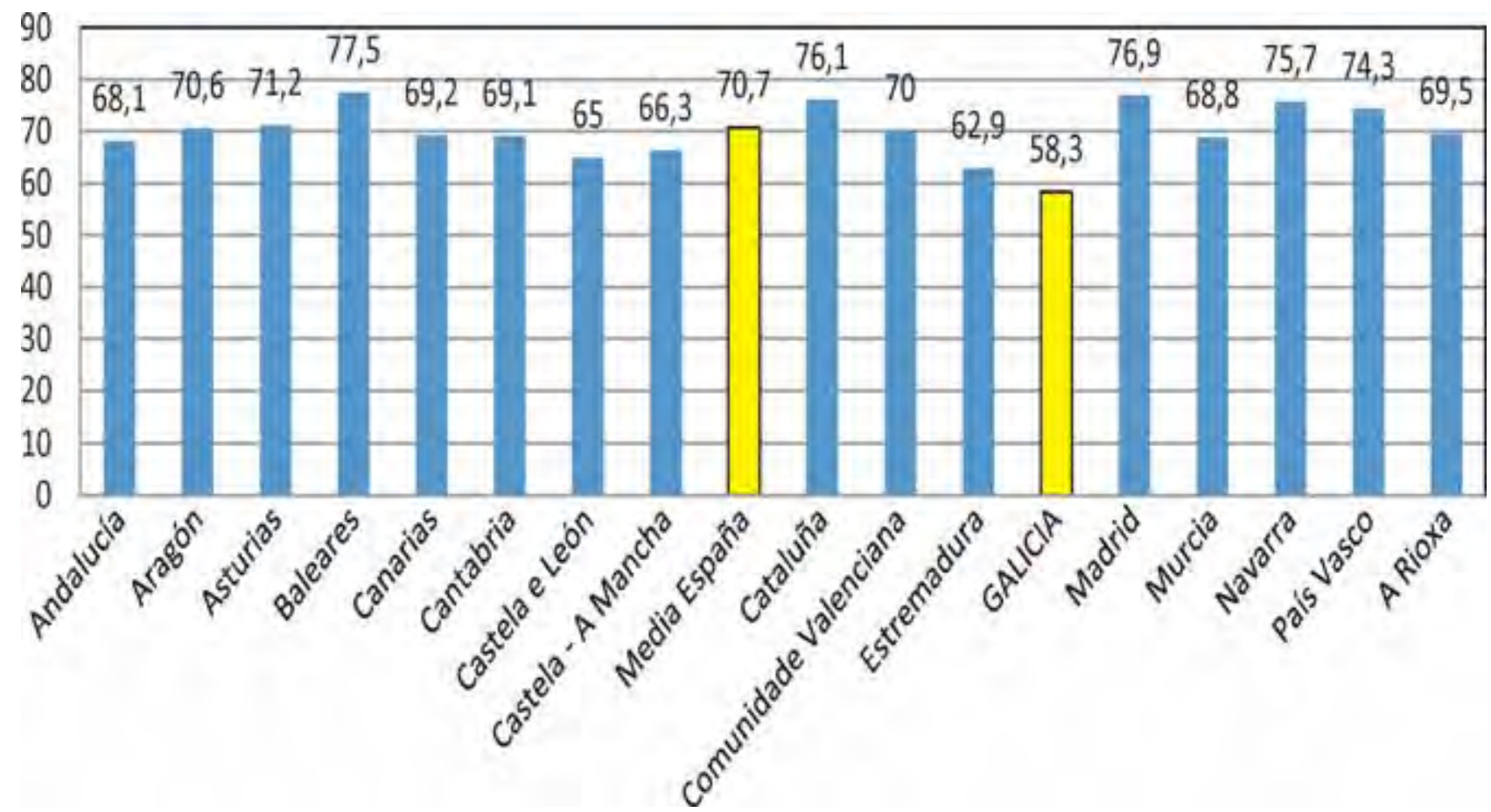

Fonte: Estudio General de Medios (EGM) 2015.

Esta situación aínda se agrava máis se se toma como referencia os indicadores da Unión Europea, onde a media xa se sitúa no 80 \% de penetración. Galicia non acada as cifras de países coma Bulgaria, que tiveron un desenvolvemento moito máis lento no seu histórico, e está moi lonxe doutros que se asemellan máis en canto á poboación, como pode ser Lituania, que acada xa a cota do $73 \%$.

Así e todo, no referido á calidade de conexión, obsérvase unha clara tendencia cara ao aumento do uso de sistemas de banda larga, fundamentalmente ADSL e cable.

O informe Diagnóstico 2013. A Sociedade da Información nos fogares galegos, elaborado pola Axencia para a Modernización Tecnolóxica de Galicia, deixa patente que a maioría dos fogares e das empresas galegas optan polas vías de alta capacidade para a súa conexión, chegando a cotas que superan o $65 \%$, con incrementos bianuais que superan o $23 \%$. A mellora dos nodos finais de conectividade, moito máis próximos aos fogares e creados con tecnoloxías dixitais, permite falar xa de niveis de cobertura de banda larga próximos á totalidade da poboación en Galicia. Aínda así, non se acadan as cotas medias da UE, pero a distancia supera lixeiramente os 10 puntos.

Este tipo de conexión de calidade ten unha especial incidencia nas contornas urbanas. Xustamente ao redor das cidades da Coruña, Vigo e Santiago é onde se producen os maiores índices de contratación de banda larga, superando as cotas do $70 \%$, máis semellantes ás medias europeas. 
Gráfico 2. Porcentaxe de usuarios de Internet por países da UE-27 no ano 2014

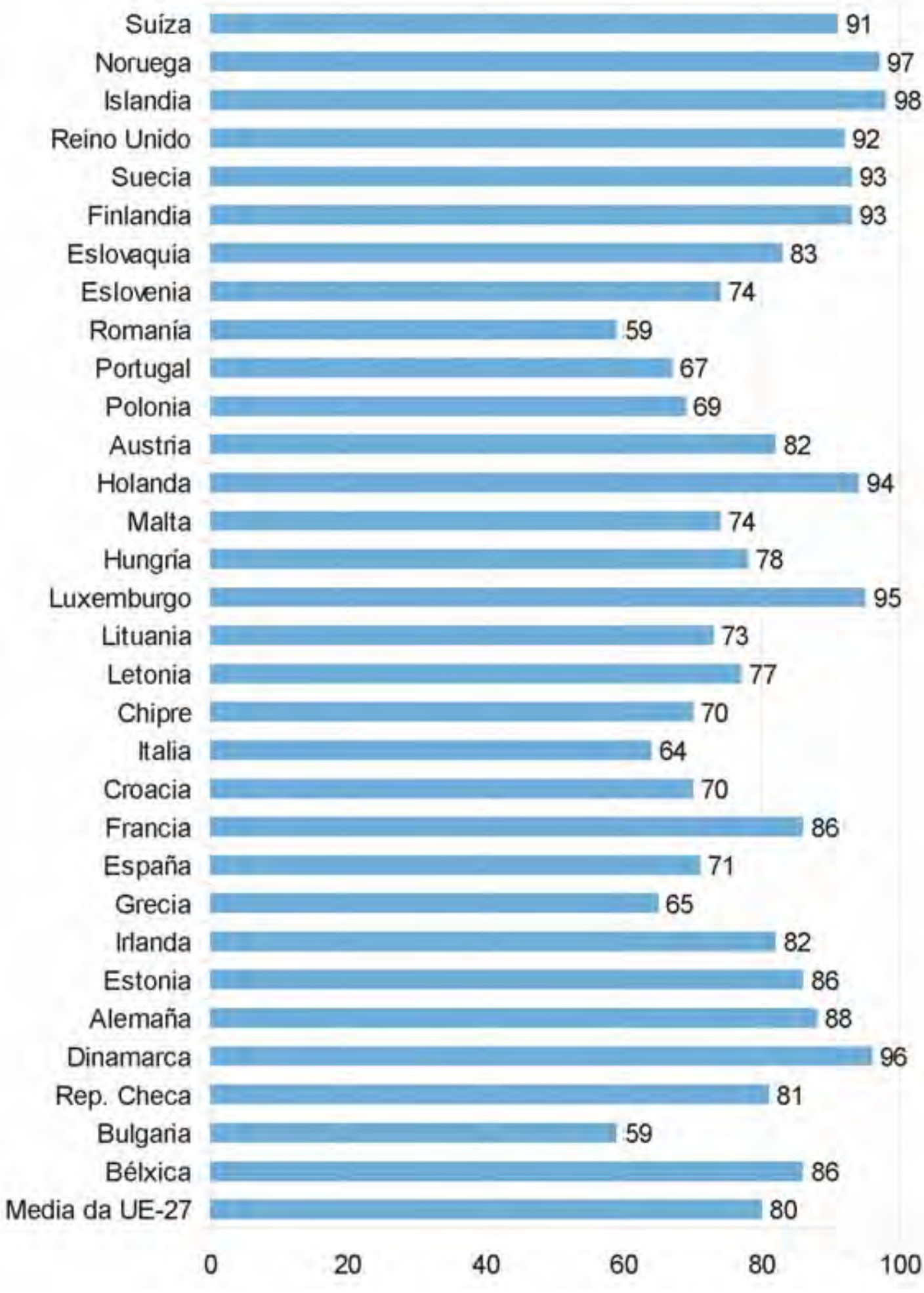
8 
Gráfico 3. Fogares conectados a banda larga e lugares onde hai máis conexión

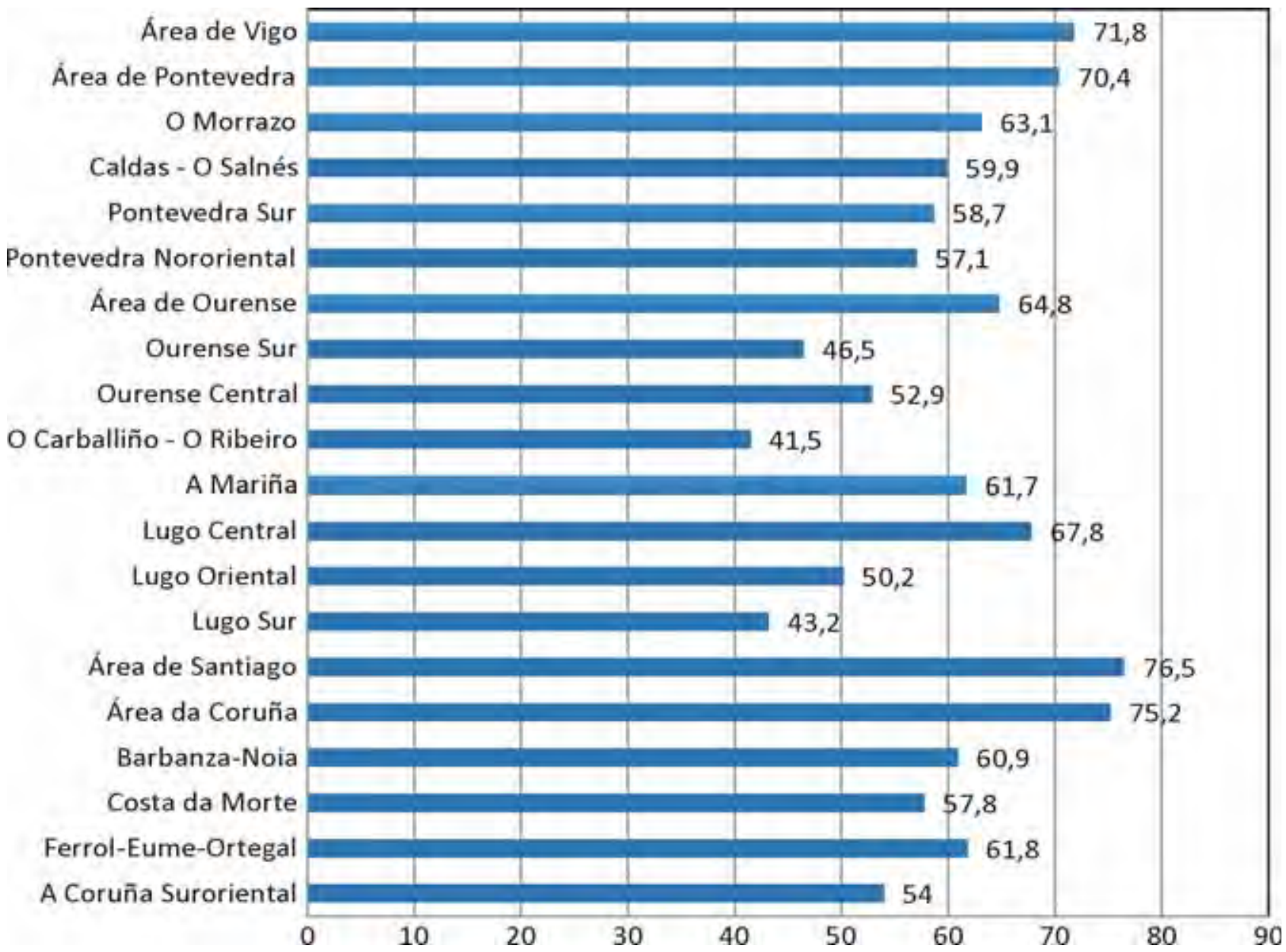

Fonte: Observatorio da Sociedade da Información e a Modernización de Galicia (OSIMGA) 2013.

Os principais condicionantes que provocan a non conectividade dentro da poboación galega fundaméntanse en tres eixes. 0 primeiro está vinculado á percepción de necesidade que pode ter o cidadán e a cidadá, o que provoca que máis da metade das persoas que non se conectan afirman que non lles resulta interesante. A segunda das caixas fundaméntase na falta de formación e de coñecementos para utilizar os dispositivos de conexión. Por último, a terceira causa principal de non conexión está directamente relacionada cos custos de conexión e de compra de equipamentos. Estas cifras están moi próximas ás medias españolas, con desviacións que raramente superan o $5 \%$.

A tendencia mundial actual en Occidente diríxese cara á creación de electrodomésticos que teñan a posibilidade de conectarse a Internet. Os que teñen unha maior penetración na actualidade son os televisores, aínda que nos últimos anos a 'internet das cousas' estase a estender a outros electrodomésticos.

O pulo desta tendencia necesariamente debe ir relacionado coa conectividade de alta capacidade e cun sistema tarifario por parte das operadoras máis dinámico que permitan, por exemplo, a combinación de varios servizos de conexión (móbil, fixa...) ou a incorporación de contidos exclusivos directamente vencellados co tipo de conexión prestado, como pode ser o caso de R ou de Movistar. 
Gráfico 4. Causas da non conexión

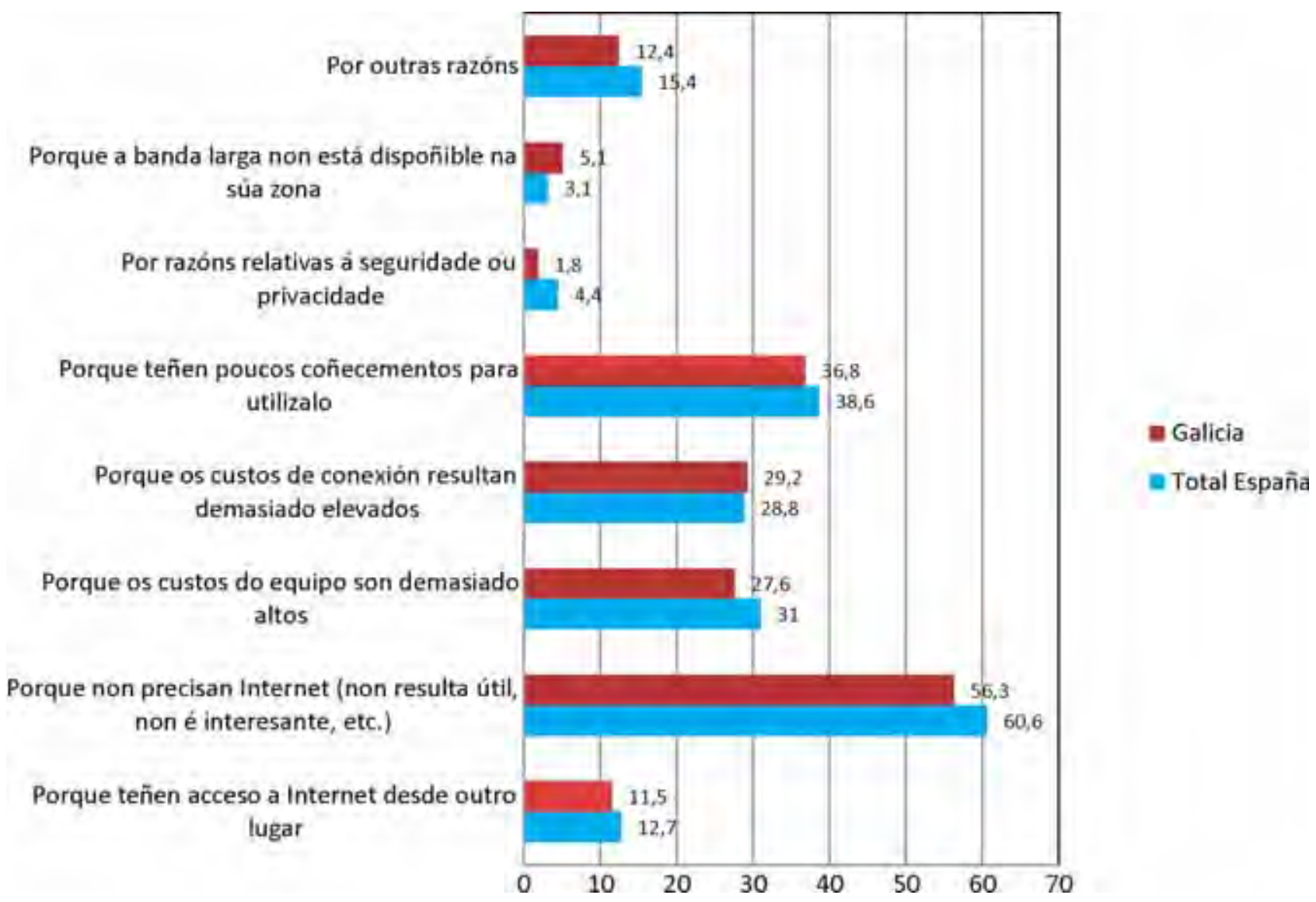

Fonte: INE 2014.

\section{SERVIZOS VINCULADOS Á SOCIEDADE DA INFORMACIÓN}

Analizada a conectividade, cómpre centrarse tamén nos servizos e no uso que fai a cidadanía das posibilidades que nos ofrece a conexión a Internet.

Igual que no informe anterior, decidiuse a análise pormenorizada da relación das e dos cidadáns coas administracións públicas, as encargadas de fomentar o uso das novas tecnoloxías. Igual que se indicaba no informe anterior, as porcentaxes de uso da poboación galega das posibilidades da administración electrónica son claramente superiores á media estatal, salientando as relacións a través de servizos web e de mecanismos de interacción activa. Destácase tamén o aumento constante do uso que fai a cidadanía das ferramentas para trasladar información e peticións á Administración, chegando a unha interesante cota que acada o $41 \%$.

Se ben a relación coa Administración é un indicador de interese, non é o uso principal da cidadanía. Os servizos máis usados non variaron ao longo dos anos, e a busca de información xunto ao envío e recepción de correo electrónico son accións habituais para practicamente o 90 \% da poboación. Merece tamén unha especial atención a variable «ler ou descargar noticias de xornais e revistas», con cotas tamén moi próximas á totalidade da información. As redes sociais continúan o seu ascenso iniciado hai dous anos, así como a banca electrónica, que aumentou o seu uso en máis de 12 puntos. Si parece estancarse o uso de Internet para vender produtos. 
Gráfico 5. Relación coa Administración

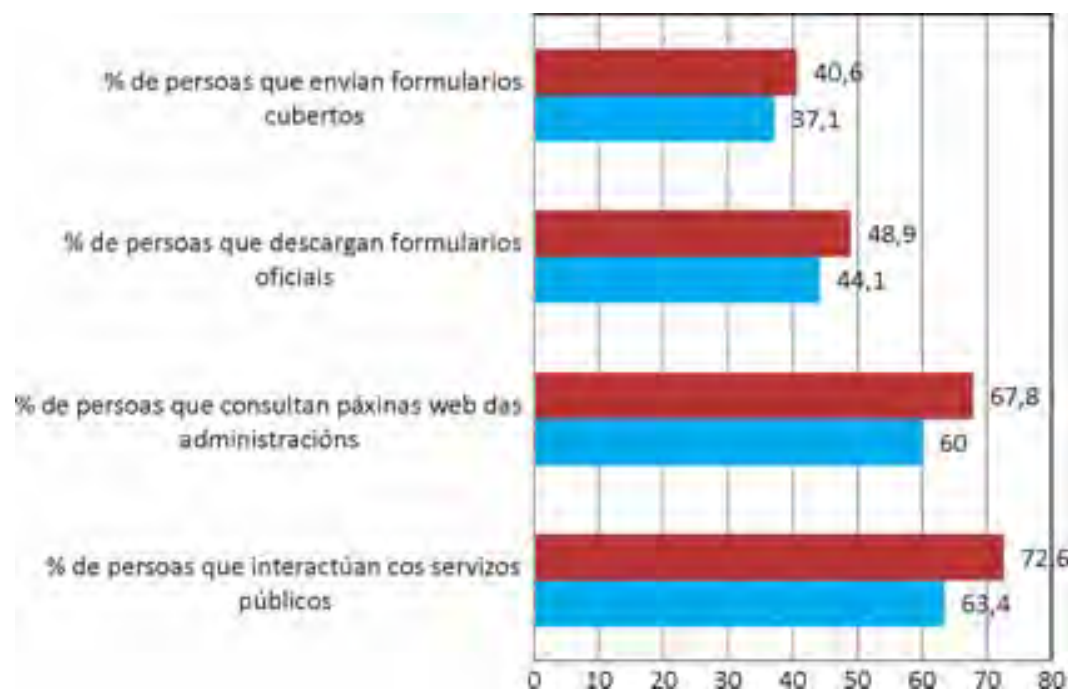

Fonte: INE 2014.

Gráfico 6. Tipoloxía do uso de Internet

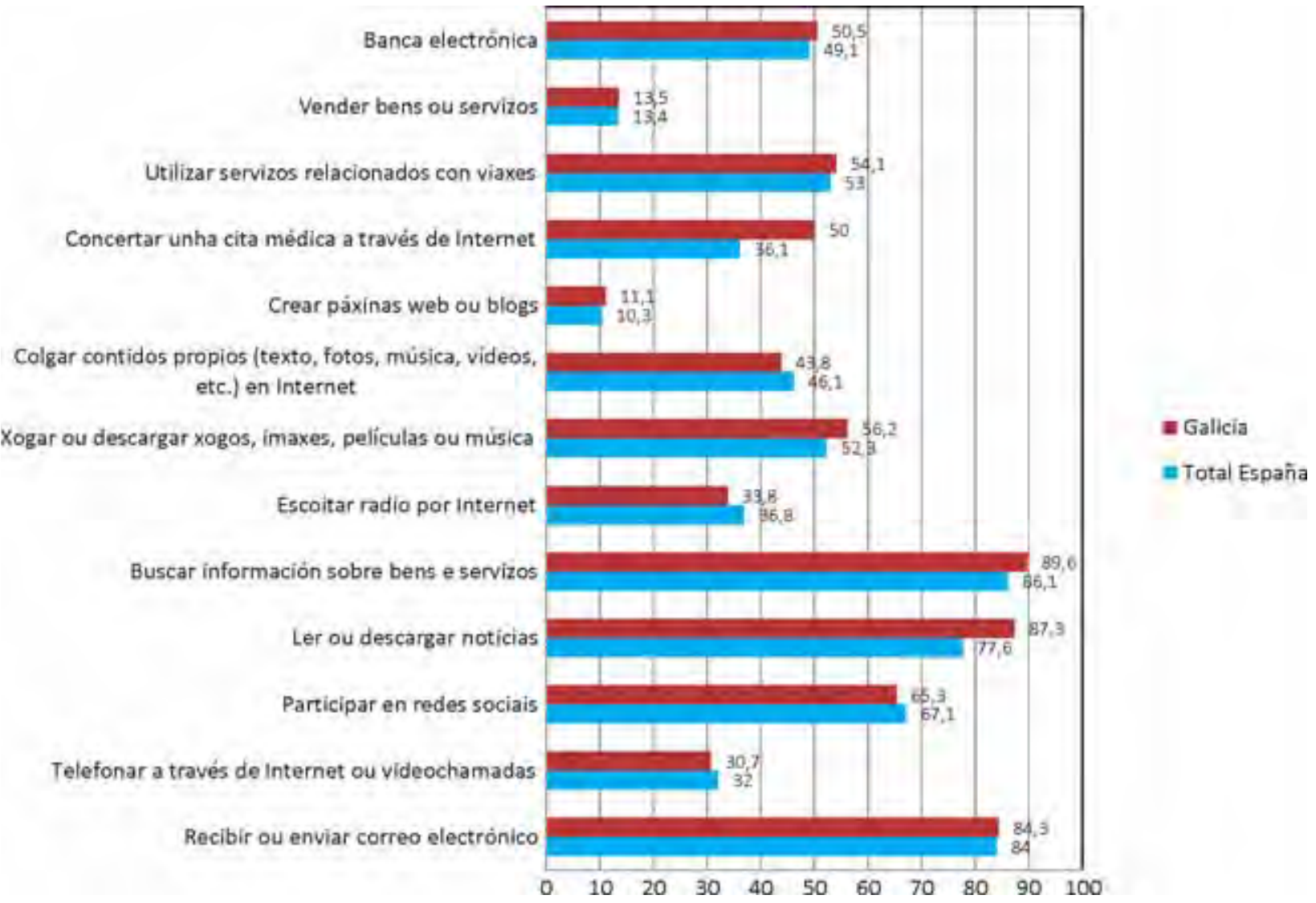

Fonte: INE 2014 
No caso dos nenos de 10 a 15 anos, as cotas de uso de tecnoloxía conectada a Internet aumenta sensiblemente con respecto ao resto da poboación, acadando case o 95 \%. É preciso tamén facer unha especial mención ao aumento progresivo de conexión dos nenos a través de tecnoloxías móbiles, ben sexan teléfonos ou ben tabletas electrónicas. De novo, os traballos escolares e as accións vinculadas ao ocio son as máis habituais neste segmento da poboación.

Gráfico 7. Uso das TIC polos nenos

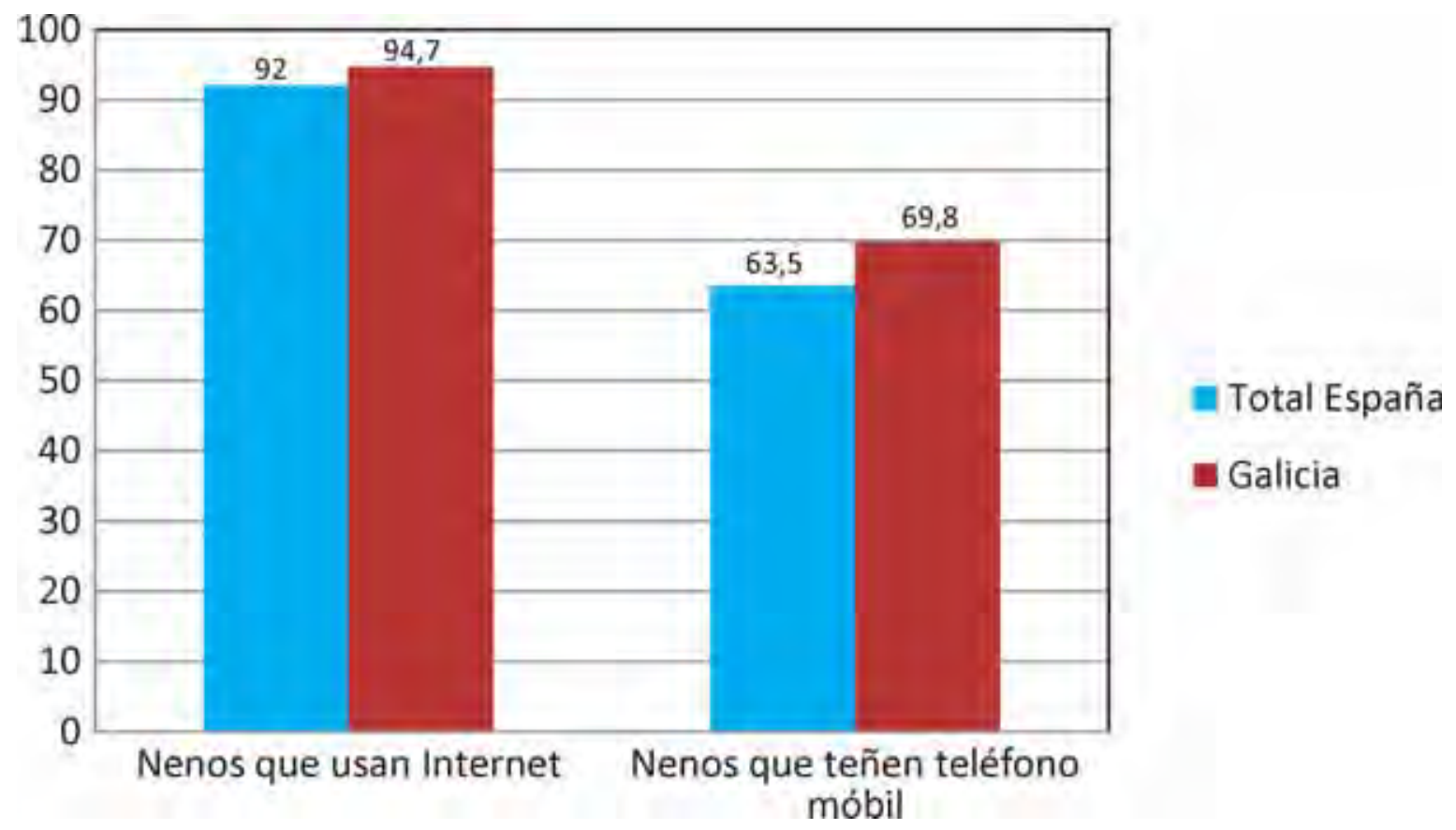

Fonte: INE 2014.

\section{ALFABETIZACIÓN DIXITAL}

Os procesos de alfabetización son unha das principais claves da evolución da conectividade dunha sociedade. Nestes procesos, cómpre facer unha distinción clara entre os denominados «nativos dixitais», cunha curva de aprendizaxe moi reducida, e as persoas que precisan investir máis tempo para aprender a usar calquera tipo de innovación que se produza neste terreo.

Nas sociedades occidentais, a tendencia é que os mozos e as mozas sexan xa nativos dixitais e que sexan os usuarios máis activos. En Galicia confírmase esa tendencia e os datos afirman que o 97,5 \% dos mozos e mozas con idades comprendidas entre os 16 e 24 anos acceden habitualmente a Internet. Estes índices son radicalmente distintos nos tramos de idade superiores aos 65 anos, onde o uso non acada a cota do $15 \%$.

Os nenos e as nenas son, ademais, un dos maiores motores da conectividade a Internet no fogar. A enquisa realizada pola Amtega sobre a Sociedade da Información nos fogares galegos indica o impacto da presenza de nenos no fogar, que provoca un aumento de 20 puntos nas cotas de conectividade. Xustamente a incorporación do uso das TIC e do acceso a Internet nos currícula de primaria permite consolidar a poboación máis nova como «nativa dixital». 
Gráfico 8. Uso de Internet segundo os tramos de idade

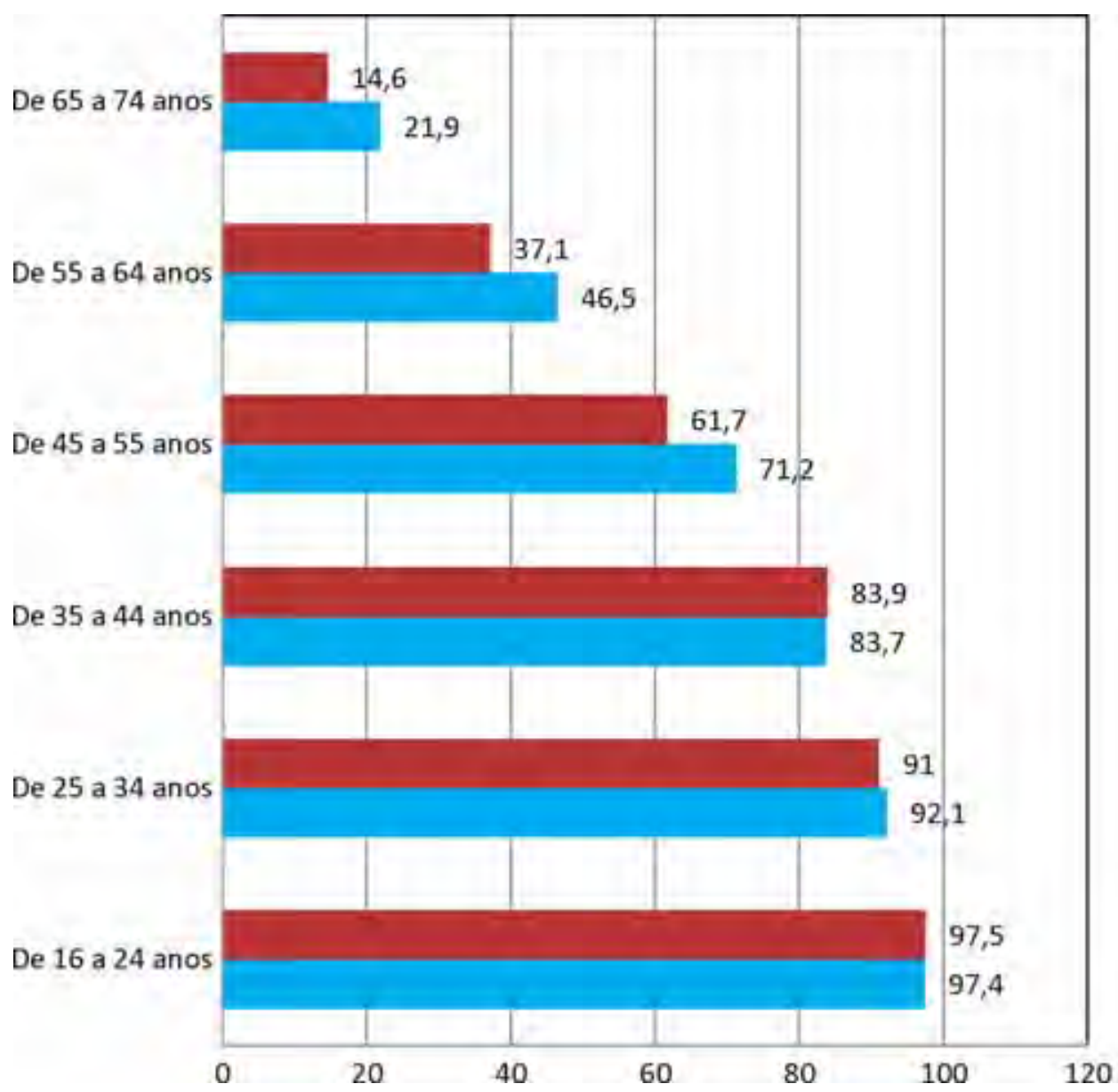

Total Galicia

Total España

Fonte: OSIMGA 2013.

Outros datos avalan tamén o grao de alfabetización dos últimos anos, por exemplo o aumento da percepción da utilidade das TIC e da conectividade a Internet. Podemos falar xa de certa unanimidade en considerar os servizos de conexión como elementos que melloran substancialmente a calidade de vida, especialmente en aspectos tan sensibles como a educación, a vida laboral ou as relacións sociais. Estes datos supoñen un importante avance na concepción da conectividade como elemento importante para poder desenvolver as tarefas diarias dun xeito máis satisfactorio.

Outro indicador de interese para comprender a consolidación da tendencia positiva de alfabetización dixital está relacionada coa autopercepción de dominio das ferramentas. En Galicia, de xeito semellante ao resto de España, practicamente a metade dos usuarios de Internet considérase avanzado ou experto, especialmente nas ferramentas máis consolidadas como pode ser a navegación por Internet, o correo electrónico ou o uso das aplicacións ofimáticas (procesadores de texto, follas de cálculo...).

Con todo, nas ferramentas máis novas, como as xestoras de redes sociais, o grao de percepción varía sensiblemente e tan só o $20 \%$ dos seus usuarios se consideran usuarios avanzados ou expertos. É importante destacar que estes datos tenden cara a unha homologación ao longo do tempo, determinando claramente que os procesos de alfabetización, especialmente nas persoas non nativas, require un período de tempo medio para poder consolidarse. 
Gráfico 9. Percepción de que as novas tecnoloxías melloran a calidade de vida. As novas tecnoloxías son boas ou moi boas para...

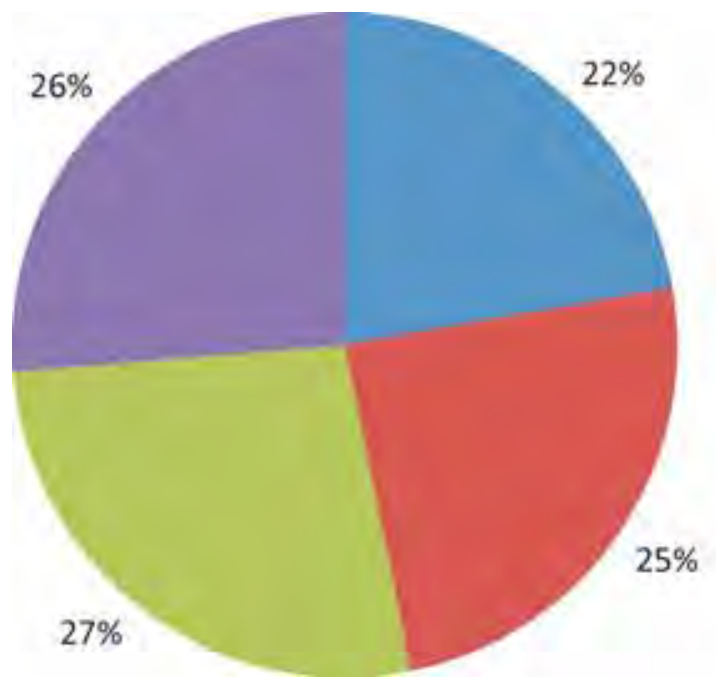

- Para relacionarse socialmente

- Para facer a vida máis sinxela

= Para a educación

Para o mundo laboral

Fonte: Observatorio Nacional de las Telecomunicaciones y de la Sociedad de la Información (ONTSI) 2014.

Gráfico 10. Percepción do coñecemento do uso das tecnoloxías

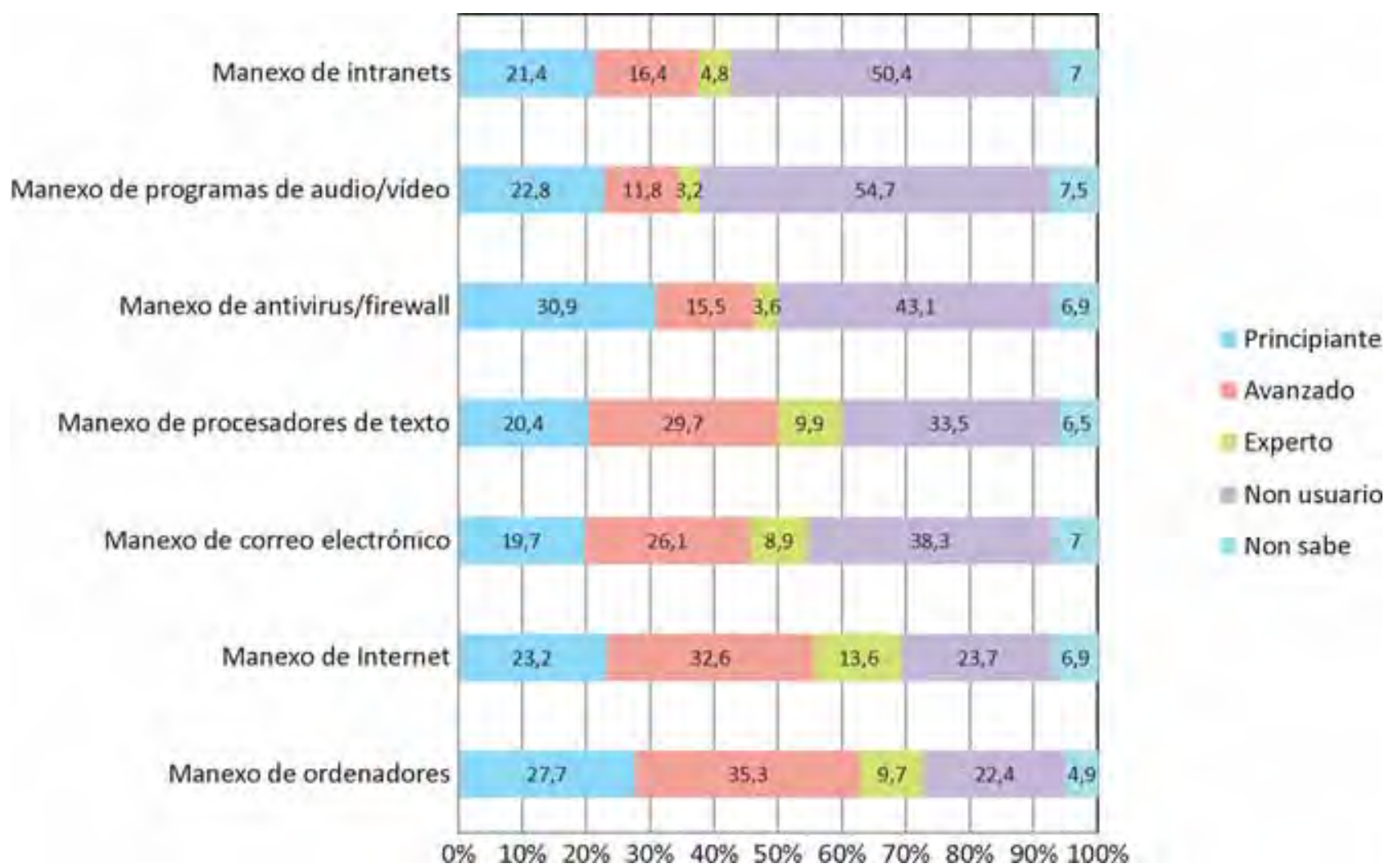

Fonte: ONTSI 2014. 
Sen dúbida, as consecuencias do coñecemento das ferramentas e da súa percepción de utilidade son as que definen o aumento da conectividade en todos os contextos, destacando sobre todo a conexión desde o fogar e desde o traballo. Lonxe quedan as primeiras estatísticas de finais dos anos 90, que deixaban patente a baixa conexión dos fogares en beneficio dos lugares de traballo e de estudos. Hoxe, queda patente que maioría dos galegos e das galegas se conectan desde lugares definidos e tan só un 7 \% da poboación segue acudindo a locutorios para poder facer as súas conexións. Pero, quizais, a principal novidade é o aumento exponencial da conexión a través de dispositivos móbiles, acadando unha cota que supera o $84 \%$ das persoas que se conectan a Internet, especialmente a través do teléfono móbil, cunha cifra que acada o $70 \%$ do total.

Gráfico 11. Lugar de conexión habitual

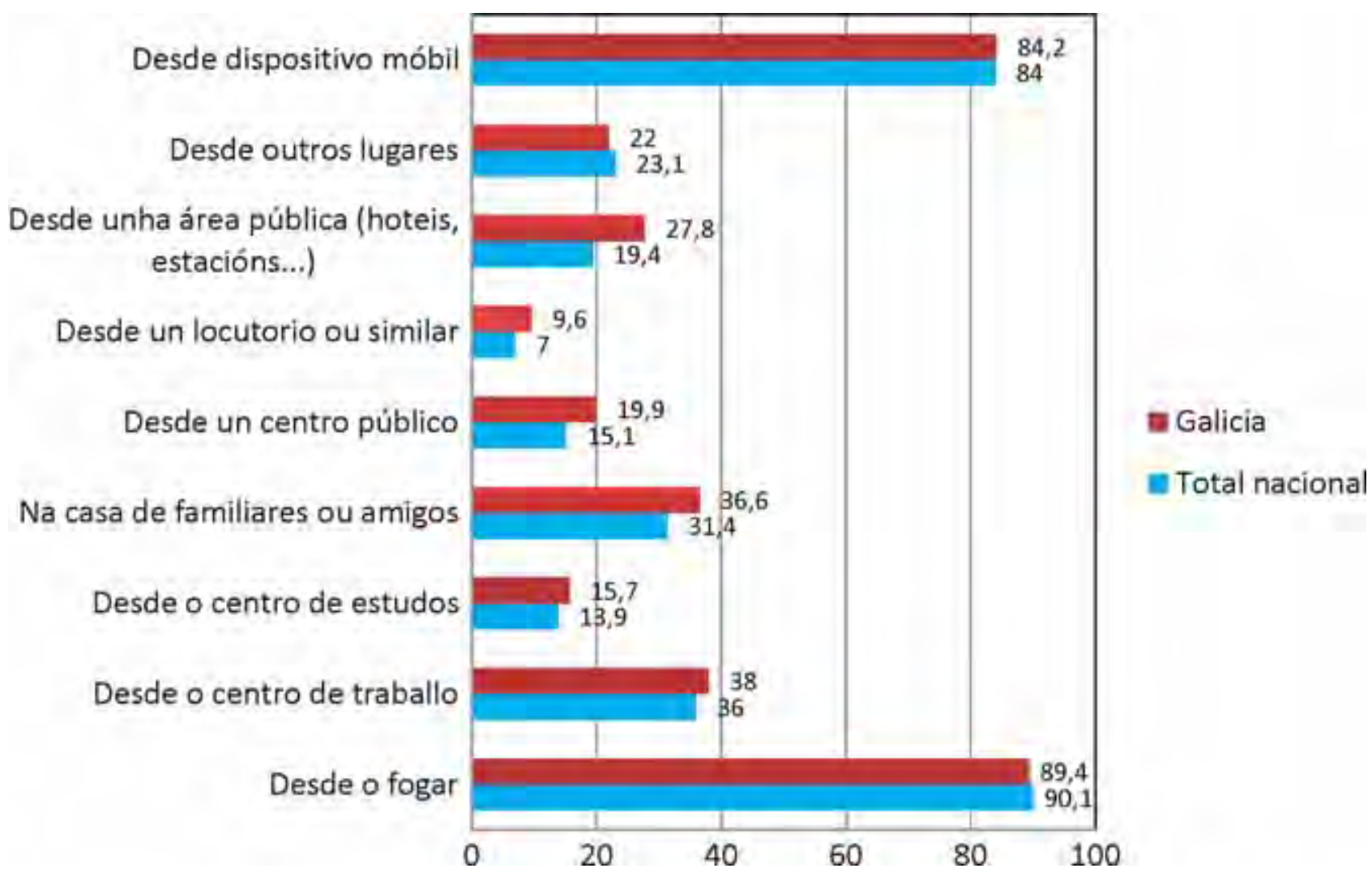

Fonte: INE 2014.

\section{CIBERMEDIOS: INCERTEZAS Á VOLTA DE 2015}

O panorama dos medios dixitais con orixe no papel apenas cambiou no interludio entre uns e outros informes da comunicación. Caracterízase polo estatismo na evolución dos cibermedios, a ausencia de innovación en contidos -agás determinados exemplos híbridos que veremos- e tímidos proxectos de muro de pagamento que non chegan a facerse efectivos.

Esta conxelación da innovación en cibermedios ten o seu correlato nunha segunda fronte: a destrución dun contorno público que poida avaliar os resultados dos cibermedios na rede, os marcos de competencia e a presenza dun dos fenómenos máis interesantes dos últimos anos: os micromedios. 
A escasa audiencia dos cibermedios galegos esvaece, ademais, os seus resultados no conxunto español. As dúas frontes tradicionais para aproximarse á audiencia galega eran o Estudio General de Medios (EGM) e as actas da Oficina de Justificación de la Difusión (OJD). No caso do EGM, a última vaga (febreiro-marzo 2015), o primeiro cibermedio galego en figurar no moi competitivo ránking de sitios web é lavozdegalicia.es, no posto vinte dun total de vinte e cinco sitios web, con 520000 visitas ao seu sitio nos últimos trinta días. O repartimento de visitantes do ránking permite, ademais, observar a evolución de Internet como un espazo de entretemento audiovisual no que os medios ocupan, cada vez máis, un punto máis especializado. Deste xeito, Youtube é o sitio web hexemónico a unha enorme distancia dos seguintes, seguido de Elpais.com, Marca, Twitter, As.com, Antena3.com, Rtve.es e Lasexta.com.

No caso de OJD Interactiva, que ofrece unha información bastante exhaustiva do comportamento da audiencia dos cibermedios a través das súas actas, nos últimos anos boa parte dos cibermedios galegos deixaron de ser auditados por ela. Só sobreviven dous: Galiciae (que aglutina Diario de Pontevedra e El Progreso) e elcorreogallego.es, dos que analizaremos as actas de xuño de 2015.

En canto a Galiciae, este produto do grupo El Progreso ten unha media diaria de máis de 35000 visitas nun contexto favorable: segundo OJD, o número de visitas por navegadores únicos pasou os últimos doce meses de preto de 250000 a máis de 400 000, o cal indica unha progresión máis que notable que non pode ser analizada en detalle debido á precariedade de datos.

Verbo de elcorreogallego.es, as estatísticas de OJD sitúan o número de visitantes medio deste produto en case 30000 visitantes, que se mantiveron estables e sen crecementos significativos durante os últimos doce meses, xerando unha media de algo máis de 400000 navegadores únicos/mes durante todo o período.

Un elemento significativo é a gran diferenza na audiencia da páxina de inicio entre elcorreogallego.es e galiciae.com. Se en elcorreogallego.es a portada supón case un 30 \% do tráfico, no caso de Galiciae a portada oficial supón menos dun $1 \%$ do tráfico total. Isto desvela que boa parte do consumo deste medio provén dos seus subdominios locais, elprogreso.galiciae.com e diariodepontevedra.galiciae.com, e sinala a dificultade por conseguir crear unha edición electrónica de ámbito galego por parte do grupo propietario.

\section{UNHA ANÁLISE DOS CIBERMEDIOS GALEGOS A TRAVÉS DE GOOGLE TRENDS}

Cremos necesario, malia as enormes dificultades técnicas e a imprecisión de moitos dos sistemas de análise baseados en datos aproximativos, prestar atención ao funcionamento global do sector de comunicación en Galicia. Para iso, empregamos a ferramenta Google Trends. A principal fonte de datos de Google Trends son as buscas dos usuarios. $\mathrm{Na}$ medida en que o comportamento de moitos usuarios na actualidade é prescindir da barra do navegador para introducir as URL e acceder, pola contra, a través de buscas en Google, Trends pode achegarnos datos interesantes que sempre van ofrecer unha maior precisión canto máis masivos sexan.

No noso estudo de cibermedios galegos realizamos unha análise dos últimos doce meses dos patróns de consumo dos cibermedios galegos, nos que podemos destacar os seguintes aspectos:

Tres escalas de audiencia. A primeira escala ocúpaa en solitario La Voz de Galicia. Malia sufrir un descenso de aproximadamente un $20 \%$ no primeiro semestre de 2015, parece remontar cara a finais deste período. $\mathrm{Na}$ segunda escala está o Faro de Vigo, ocupando unha posición intermedia entre La Voz de Galicia e a terceira escala. Na terceira escala están os xornais de ámbito máis local, cunha posición moi baixa e no límite da visibilidade. É neste espazo onde o sistema comeza a transformarse e se observa a competencia entre estes medios de carácter moi local e iniciativas xornalísticas de nacenza dixital con maior ou menor veteranía.

Permanencia do ámbito de influencia local. A análise de Google Trends revela como os medios galegos teñen tráfico de audiencia basicamente residual procedente do exterior. O seu consumo é esencialmente de ámbito 
autonómico e moi vinculado ás súas áreas de influencia orixinais do papel, pero que tamén están presentes no seu contido editorial.

Consumos complementarios. Google Trends permite comprobar que os medios son consumidos na rede de forma complementaria. Nas buscas relacionadas con cada un dos termos podemos observar como os usuarios tamén consomen medios da competencia, medios especializados (deportivos) e medios de ámbito español (sobre todo EI País e, en menor medida, El Mundo). Na medida en que o medio ten unha implantación e un número de buscas maior, aparece tamén a combinación coas redes sociais, pouco apreciable nas buscas relacionadas dos usuarios que consomen medios pequenos.

\section{MUROS DE PAGAMENTO E OUTROS SISTEMAS DE FINANCIAMENTO}

No contorno dixital, os cibermedios galegos seguen a basear os seus ingresos esencialmente nas canles publicitarias, se ben nos últimos anos houbo diferentes movementos que apuntan dun xeito tímido cara a un cambio do modelo de negocio que aínda está por ver se se implementará definitivamente. Podemos distinguir catro estratexias diferentes en relación con modalidades distintas de obtención de ingresos.

a) Previsualización e rexistro gratuíto: é o modelo seguido por La Voz de Galicia. A partir da detección da frecuencia de uso do medio por parte do usuario, La Voz de Galicia obriga a un rexistro para continuar.

b) Previsualización e subscrición: é o caso do Faro de Vigo. A partir dun determinado número de consultas ao medio, este péchase e ofrece unha subscrición a un prezo moi competitivo (30€ ano).

c) Avance de contido: o medio ofrece o corpo de titulación, entradiña e, ás veces, o seguinte parágrafo, remitindo ao lector á edición en papel (ou a algunha plataforma como pode ser Orbyt, no caso de El Correo Gallego). É o caso de El Correo Gallego, El Progreso ou Sermos Galiza.

d) Doazón voluntaria: máis propio de medios nacidos electrónicos, este recurso é practicado por Galicia Confidencial ou Praza Pública. Ás veces, este sistema de doazóns compleméntase con servizos premium para os usuarios que ingresan diñeiro para o medio.

O resto dos medios empregan fórmulas de carácter publicitario para a obtención de resultados económicos, permitindo un libre acceso ao contido.

\section{OS MICROMEDIOS: UN SOPORTE DE DIFÍCIL MONETIZACIÓN}

A crise económica, os cambios no sector da comunicación e a dinámica de transformación das redes sociais provocaron estes anos o nacemento do que se definiu como micromedios: as cabeceiras mantidas por usuarios ou pequenos grupos de particulares que inclúen as diferentes dinámicas propias dun medio de comunicación pero a pequena escala: elaboración de contidos xornalísticos, facturación publicitaria ou por outras vías.

Por unha banda, xornalistas que procedían de medios de comunicación tradicionais construíron pequenos medios de comunicación na procura de espazos de nicho temáticos ou locais. Canda medios xa veteranos como Galicia Confidencial ou Disque Cool, únense outros como Pontevedra Viva, Mundiario, Stadio Sport, Dxtbase.com, Trueiro, Benbo, Magazine Cultural M, La Alacena Roja, etc. Non é o propósito do informe recoller a grande explosión de publicacións que, como as previamente citadas, explotan medios de nicho ou locais moi distintos, desde información deportiva ata gastronómica. Un aspecto salientable é a creación, desde Ourense, de Opennemas, unha interesante 
iniciativa que ofrece software de publicación xornalística gratuíto a base de compartir resultados publicitarios, e con diferentes modalidades de prezos para ampliar posibilidades técnicas. Opennemas está promovido pola empresa Openhost.

Por outra banda, os blogs -que foran tan relevantes para a cultura e a lingua galegas a mediados da década pasada- foron migrando cara a redes sociais propietarias e privadas como Facebook ou Twitter; os blogs superviventes profundaron no camiño da especialización temática. O panorama é notablemente distinto, polo tanto, ao da década anterior: os blogs foron asumidos como ferramentas de comunicación corporativa -tanto por parte das empresas da cultura como por todo tipo de entidades pequenas públicas e privadas- e tamén como formas de expresión da marca persoal, canda as redes sociais de capital privado. 


\section{REFERENCIAS BIBLIOGRÁFICAS}

CASTELLS, M. (2009): Comunicación y poder, Madrid, Alianza Editorial.

FogeL, J. F. (2007): La prensa sin Gutenberg: el periodismo en la era digital, Madrid, Punto de Lectura.

EGM (2015): Resumen general de resultados. Octubre 2014-mayo 2015 (http://www.aimc.es) [última consulta: 24/04/2015]. OSIMGA (2014): A Sociedade da Información nos fogares galegos. Ano 2013, Santiago de Compostela, Xunta de Galicia.

ONTSI (2014): Las TIC en los hogares españoles. Estudio de demanda y uso de Servicios de Telecomunicaciones y Sociedad de la Información, Madrid, Gobierno de España.

\section{BASES DE DATOS UTILIZADAS}

Eurostat

INEBase

IGE 